\title{
Governos de Coalizão nas Democracias Presidencialistas e Parlamentaristas*
}

\author{
José Antonio Cheibub, Adam Przeworski e Sebastian Saiegh
}

\section{INTRODUÇÃO}

$\mathrm{O}$

mantra que se repete em uníssono a respeito do presidencialismo e do parlamentarismo diz que: (1) parlamentarismo e presidencialismo são regimes diferentes: o primeiro é um sistema de "dependência mútua", o segundo, um sistema de "independência mútua" entre o Executivo e o Legislativo (Stepan e Skach, 1993:17-18; Linz, 1994:64; Linz e Stepan, 1996:181); (2) as instituições criam incentivos: no presidencialismo os incentivos para formar coalizões são mais escassos e mais fracos do que no parlamentarismo (Mainwaring, 1990; Stepan e Skach, 1993:20; Mainwaring e Scully, 1995:33; Linz e Stepan, 1996:181; Huang, 1997:138); (3) coalizões são difíceis e muito raramente, "apenas excepcionalmente" (Linz, 1994:19), se formam no presidencialismo; (4) quando nenhuma coalizão é formada em um sistema presidencialista, a conseqüência é um "impasse parlamentar de longa duração" (Linz e Stepan, 1996:181), "não existe alternativa a

\footnotetext{
* Agradecemos os comentários de John Ferejohn, Fernando Limongi, John Londregan e Iain McLean. Nathan Jensen colaborou na coleta de dados. [A tradução do original em inglês "Government Coalitions under Presidentialism and Parliamentarism" é de Vera Pereira e a revisão técnica é de José Antonio Cheibub.]
}

DADOS - Revista de Ciências Sociais, Rio de Janeiro, Vol. 45, nํ2, 2002, pp. 187 a 218. 
não ser o impasse" (Mainwaring e Scully, 1995:33), "um governo conflituoso é a norma" (Jones, 1995:38). Como conseqüência, "a própria noção de governo majoritário é problemática nos sistemas presidencialistas que não têm um partido majoritário" (Huang, 1997:138); "uma democracia presidencialista multipartidária estável [...] é difícil" (Mainwaring, 1990:168); "os sistemas presidencialistas que sistematicamente negam ao presidente suficiente base de apoio parlamentar tendem a não prosperar" (Jones, 1995:38).

Presidencialismo e parlamentarismo são, de fato, diferentes e as instituições claramente criam incentivos. Mas que características institucionais dos dois sistemas forjam os incentivos relevantes para a formação de coalizões? Quais são esses incentivos? É esta diferença suficiente para impedir a formação de coalizões em sistemas presidencialistas multipartidários? É o impasse parlamentar, o governo conflituoso, a crise da democracia, ou outro tipo de desastres, o que se observa quando o presidente não consegue formar uma coalizão?

E são as coalizões realmente excepcionais nos sistemas presidencialistas multipartidários? É verdade que quando as coalizões não se formam os presidentes são ineficazes em termos legislativos? A democracia fica verdadeiramente ameaçada? Note-se que estas afirmações são oferecidas como generalizações indutivas, ao mesmo tempo que são acompanhadas por exortações à coleta de dados (ver, p. ex., Mainwaring e Shugart, 1997:336n). São generalizações feitas a partir de observações ainda por fazer.

Nosso objetivo é pouco mais do que fazer uma lista das diferenças entre os dois sistemas que possa explicar os padrões de formação de coalizões neles observados. Tudo o que fazemos é tomar um modelo-padrão de formação de coalizões no parlamentarismo, introduzir as modificações necessárias e aplicá-lo ao presidencialismo.

Mostrar o óbvio - isto é, que no parlamentarismo todos os governos precisam de maioria no Legislativo, posto que, caso contrário, novas eleições são convocadas, enquanto no presidencialismo o presidente pode sofrer oposição de uma maioria parlamentar - é constrangedoramente tedioso. Mas também surpreendentemente fecundo, pois nos leva a concluir que, nos dois sistemas, governos minoritários só ocorrem quando a política se aproxima do ponto ideal do governo. Portanto, governos minoritários de um único partido não são neces- 
sariamente menos eficientes do ponto de vista legislativo do que governos de coalizão majoritária. Como isso é também verdade nos sistemas presidencialistas, nenhuma das proposições sobre o impasse legislativo, os governos conflituosos e a instabilidade democrática se seguem da "inabilidade" de se formar coalizões nesses sistemas.

Começamos com uma análise do processo de formação de coalizões no parlamentarismo e no presidencialismo. Procurando descobrir as diferenças institucionais entre os dois sistemas que poderiam afetar os incentivos para a formação de alianças, concluímos que a distinção básica está no que resultaria da não-formação de uma aliança, isto é, no "ponto de reversão". No parlamentarismo, o ponto de reversão é uma eleição antecipada; no presidencialismo, é uma situação em que o partido do presidente controla todas as pastas ministeriais e as políticas são estabelecidas no ponto ideal do presidente. Uma das conseqüências desse fato é que no parlamentarismo todos os governos têm o respaldo de uma maioria parlamentar; quando isto não acontece, ou bem se reforma a coalizão ou novas eleições devem ser convocadas. No presidencialismo, porém, um governo minoritário pode sofrer oposição de uma maioria parlamentar. Portanto, dependendo da distribuição de preferências sobre políticas e das perspectivas eleitorais dos diferentes partidos, há três resultados possíveis em sistemas parlamentaristas multipartidários: formação de uma coalizão ministerial majoritária; formação de um governo de minoria apoiado por uma maioria parlamentar; convocação de novas eleições. No presidencialismo, enquanto o terceiro resultado não é possível, uma coalizão ministerial minoritária pode se confrontar com uma maioria parlamentar.

Isto simplesmente reafirma o óbvio. Mas também nos permite concluir que as circunstâncias sob as quais coalizões ministeriais se formam ou não são as mesmas nos dois sistemas. Além disso, contrariando uma interpretação muito difundida (Mainwaring, 1993; Mainwaring e Scully, 1995:33; Mainwaring e Shugart, 1998; Valenzuela, 1998:124), somos levados a concluir que o efeito de um aumento da fragmentação é indeterminado nos dois sistemas. Em ambos, as coalizões ministeriais se constituem quando o partido formador (o maior no parlamentarismo; o do presidente no presidencialismo) opta por políticas que se situam longe da preferência do partido que lhe está mais próximo no espectro político. Quando as preferências do partido formador e de algum outro (ou outros) com o qual ele constitui uma maioria es- 
tão próximas, o partido formador não tem nenhum incentivo para oferecer pastas ministeriais a outros partidos. Se isto é verdade, então os governos minoritários não devem ser a causa de desastre, seja qual for o sistema.

O que se deve observar a partir desta análise? Dado que a distribuição de cadeiras legislativas é praticamente idêntica nos dois sistemas, e assumindo-se uma mesma distribuição de preferências políticas em ambos, a freqüência de governos minoritários seria idêntica nos dois sistemas se eleições antecipadas não fossem possíveis em regimes parlamentaristas. Segue-se, portanto, que a única diferença entre a freqüência de coalizões no parlamentarismo e no presidencialismo advém da freqüência de eleições antecipadas. Enquanto é verdade que nos sistemas parlamentaristas as crises de coalizão podem ser resolvidas através de eleições, o que não é possível nos sistemas presidencialistas, não há razão para que se suponha que as coalizões sejam excepcionais nos sistemas presidencialistas. Ademais, a nossa análise sugere que, em ambos os sistemas, não se deve esperar a ocorrência de desastres quando as coalizões não se formam.

Com base em um conjunto de dados que abrangem todas as democracias ${ }^{1}$ entre 1946 e 1999, concluímos que as previsões trágicas mencionadas no início deste trabalho são não só desprovidas de fundamento quanto amplamente falsas. Governos de coalizão são mais freqüentes no parlamentarismo, mas esta é uma diferença de grau, não de espécie. Legislativos altamente fragmentados favorecem coalizões em ambos os sistemas. Governos minoritários de partido único não são menos eficientes no Legislativo do que governos de coalizão, minoritários ou majoritários. Mesmo quando ocorre paralisia legislativa no presidencialismo, ela se deve simplesmente ao fato de que não existe coalizão que prefira uma política alternativa ao status quo. Estas conclusões não exoneram o presidencialismo. Przeworski et alii (2000) mostram que, mesmo se se considera suas condições de origem e funcionamento, as democracias presidenciais têm vida mais curta do que as parlamentares. A seqüência que quase todo mundo parece ter adotado como explicação deste fato é a seguinte: (1) a formação de coalizões é mais difícil no presidencialismo; (2) quando uma coalizão não se forma, a conseqüência é um impasse legislativo; (3) tendo em vista a paralisia legislativa, mecanismos extraconstitucionais são acionados para romper o impasse político. Contudo, nós mostraremos adiante que a diferença na freqüência de coalizões é pequena e que a as- 
sociação entre coalizões e eficácia legislativa é, na melhor das hipóteses, duvidosa. Cheibub (2002) demonstrou que as democracias presidencialistas não são mais passíveis de queda sob condições de impasse legislativo. Ademais, nos nossos dados, democracias presidenciais são igualmente vulneráveis, sejam os governos de coalizão ou não. Portanto, ainda que seja verdade que as democracias presidencialistas tendem a durar menos que as democracias parlamentaristas, cada passo na explicação deste fato é falho. Linz (1994) deve estar certo quando diz que há algo errado com os regimes presidencialistas, ainda que não tenhamos conseguido estabelecer qual das centenas de razões que ele propõe é a que realmente importa.

\section{COALIZÕES NO PARLAMENTARISMO E NO PRESIDENCIALISMO}

Consideremos o processo de formação de coalizões no parlamentarismo e no presidencialismo. Nossa estratégia é tomar uma classe especial de modelos, desenvolvida para o parlamentarismo por Austen-Smith e Banks (1988)², incorporar as características institucionais que distinguem o presidencialismo, e estudar as diferenças entre os dois sistemas.

Para que possamos introduzir o esquema geral, levemos em conta uma assembléia composta de $j \varepsilon J$ partidos $^{3}$, com pontos ideais de políticas $x^{j}$ situados em uma linha real. Os partidos derivam utilidades transferíveis das pastas ministeriais (e vantagens associadas) e utilidades não transferíveis da política:

$$
U^{j}(g, x)=g j-\left(x-x^{j}\right)^{2}
$$

onde $g$ representa a proporção de pastas ministeriais, $\Sigma_{j} g^{j}=G$ é o valor para qualquer partido associado com o controle de todas as pastas ministeriais, e $x$ é a política adotada. Note-se que esta hipótese sobre a função de utilidade, apesar de usual, não é inócua, pois ela implica que, quando a política se encontra distante do ponto ideal de um partido, este tem interesse em trocar ministérios por uma política mais próxima de seu ponto ideal. Uma justificativa para esta formulação é a seguinte: embora não haja incerteza quanto à distribuição de pastas, os resultados de políticas específicas são incertos e os partidos são avessos aos riscos. Se até aqui temos nos referido de maneira mais ou menos vaga às coalizões "de governo", é importante que façamos algumas distinções. Coalizões podem ser de dois tipos: 
Definição 1. Uma coalizão ministerial é um grupo de legisladores pertencentes a partidos que ocupam cargos de gabinete. O governo é uma coalizão ministerial se $0<g^{j}<G$ para alguns $j \varepsilon J$.

Definição 2. Uma coalizão parlamentar é um grupo de legisladores pertencentes a diferentes partidos que votam da mesma maneira.

As duas coalizões não são necessariamente coextensivas. Um partido pode não ser membro de uma coalizão ministerial e, no entanto, votar com o governo (ou, pelo menos, não votar contra ele) em algumas ou todas as matérias. Este foi, por exemplo, o caso do Partido Comunista Francês depois de abandonar o governo socialista em 1983: aprisionado à esquerda dos socialistas, restava ao PCF apoiar as propostas socialistas ou abster-se, dando ao governo maioria legislativa. Ainda mais importante, do nosso ponto de vista, no presidencialismo, uma coalizão parlamentar majoritária pode fazer oposição à coalizão ministerial. O caso de Salvador Allende, no Chile, é um bom exemplo.

As coalizões parlamentares podem variar de uma questão para outra. Essas variações podem ter como origem o fato de que os partidos votam juntos em algumas matérias mas não em outras, ou a falta de disciplina entre os membros de um partido ${ }^{4}$. Embora estas variações não sejam aqui explicitamente modeladas, uma solução razoável é conceber a política $x$ como de valor médio de um conjunto de questões. Com base nessas distinções, podemos afirmar o óbvio.

Proposição 1. No parlamentarismo, cada coalizão ministerial conta com o apoio de uma maioria parlamentar. Caso contrário, ocorre uma eleição.

A primeira parte da proposição foi comprovada por Austen-Smith e Banks (1988, Proposição 1) sob a suposição de que o ponto de reversão é um governo interino. A definição do ponto de reversão como uma eleição antecipada torna a demonstração ainda mais tediosa, visto que isto multiplica o número de casos que é preciso examinar. Como a lógica da prova permanece a mesma, reportamos o leitor à fonte original ${ }^{5}$.

A intuição é a seguinte: consideremos uma assembléia composta de três partidos, $j \varepsilon\{A, B, C\}$, onde estas letras também denotam a cardinalidade das cadeiras legislativas que cada partido controla. Suponhamos que nenhum partido detém a maioria. Definamos o protocolo de barganha fixo ${ }^{6}$ como $A>B>C$; portanto, $A$ é o primeiro partido 
formador; se $A$ não conseguir formar a coalizão, $B$ torna-se o formador; se $B$ fracassar, $C$ faz uma tentativa; se $C$ também fracassar, segue-se ponto de reversão qualquer.

O partido $A$ considera se deve fazer uma oferta que induza um dos partidos a entrar em uma coalizão ministerial. $A$, o primeiro a agir, antecipa todo o processo. $A$ sabe que o ponto de reversão não ocorrerá na última fase se $B$ e $C$ puderem formar uma coalizão que os deixe em uma situação no mínimo tão boa quanto a do ponto de reversão. $A$ também sabe que, se não formar uma coalizão $\operatorname{com} C$, este vai querer, em uma segunda fase, aceitar a oferta de $B$, que não aceitará a oferta de $A$ na primeira fase. Portanto, se $A$ e $B$ ocupam posições à parte no espaço político, de modo que uma coalizão $\{C B\}^{7}$ seja custosa para $A$ em termos de políticas, $A$ oferece ministérios a $C$ em troca de apoio a políticas que estejam mais próximas do ponto ideal de $A$. Se $B$ estiver próximo de $A$ em termos de preferências políticas (ou se $A$ for o partido de centro), $A$ forma um governo de minoria e obtém uma maioria parlamentar ao estabelecer políticas localizadas no ponto ideal de $B$ (ou no seu próprio). Suponhamos agora que $A$ saiba que a coalizão $\{C B\}$ não se formará e também que $A$ aceitaria a oferta de $B$ se ele não conseguir formar uma coalizão com $C$. Se, em vez do ponto de reversão, ambos, $A$ e $C$, preferem uma política situada no ponto médio entre os dois, $A$ forma um governo de minoria, estabelece políticas próximas de $C$ e obtém uma maioria parlamentar. Finalmente, suponhamos que os valores do ponto de reversão sejam tais que nem a coalizão $\{C B\}$ nem a $\{B A\}$ se formem. Neste caso, se uma coalizão $\{A C\}$ puder constituir-se, ela será ao mesmo tempo uma coalizão parlamentar e ministerial. Do contrário, ocorre o ponto de reversão.

Em um certo sentido, esta conclusão é óbvia: com quem poderá um partido se aliar se ninguém quer entrar em uma coalizão? Por isso, a questão principal é como pensar o ponto de reversão. No modelo de Austen-Smith e Banks (1988:407), o ponto de reversão é artificial e insatisfatoriamente justificado. Tudo o que eles dizem é que "Caso um governo não possa ser formado, constitui-se um governo interino que, por suposição, define resultados legislativos de forma 'eqüitativa'", palavra que interpretam como se referindo a uma situação onde ministérios e políticas são alocados de forma que cada partido receba uma utilidade igual a zero. Porém, é o valor que associam ao ponto de reversão que os leva a concluir que coalizões parlamentares ou ministeriais sempre se formam. Mais sensatamente, Kalandrakis (2000) 
define o ponto de reversão como sendo um governo "técnico", no qual nenhum dos partidos controla pastas ministeriais $\left(g^{j}=0\right.$ para todos $j \varepsilon J$ ) e a política é um meio-termo entre posições extremas. Mas esta definição do ponto de reversão também torna a formação de uma coalizão inevitável, posto que agora o ponto de reversão simplesmente estipula que não há pastas a serem distribuídas.

Tal como demonstrado por Diermeier e Merlo (2000), este não é necessariamente o caso quando o ponto de reversão é definido como sendo uma nova eleição. Conceba o ponto de reversão como uma eleição antecipada quase que instantânea. O valor do ponto de reversão, neste caso, depende das expectativas dos partidos quanto aos resultados dessa eleição. Se pelo menos dois partidos acreditam que terão um bom desempenho eleitoral, nenhuma coalizão será formada. Um exemplo possível seria, no caso da Espanha, se a Izquierda Unida (IU) e o Partido Socialista (PSOE) achassem que poderiam derrotar o Partido Popular (PP), ou se a IU e o PP acreditassem ter condições de ganhar do PSOE. Portanto, se o ponto de reversão for definido como uma eleição antecipada, ele pode ocorrer quando pelo menos dois partidos esperam melhorar sua situação em conseqüência dessa eleição.

Como conclusão, no parlamentarismo, governos minoritários somente sobrevivem se contam com uma maioria parlamentar. Suponha um governo que não tenha essa maioria. Isto significa, necessariamente, que existe uma combinação de ministérios e de políticas que seja melhor para alguma maioria. Um dos atributos definicionais do parlamentarismo é precisamente o fato de que uma maioria pode rejeitar o governo a qualquer momento. É possível que o governo seja minoritário e que a oposição derrote o governo em questões específicas. Mas o fato é que, se existe um governo, não existe uma maioria que queira substituí-lo. Assim, os dois resultados possíveis no parlamentarismo são um governo com maioria parlamentar, seja qual for a composição e o tamanho deste governo, ou a ocorrência imediata de novas eleições.

Proposição 2. No presidencialismo é possível que uma coalizão parlamentar majoritária não controle nenhum ministério (ver demonstração na última seção). 
Existem três diferenças institucionais entre parlamentarismo e presidencialismo relevantes para os nossos propósitos. A primeira é que, no presidencialismo, todo e qualquer governo deve incluir o presidente, portanto, a não ser que o presidente seja um político independente $^{8}$, o partido do presidente deve fazer parte de todo e qualquer governo. Assim, o espaço das coalizões ministeriais possíveis é menor em regimes presidencialistas do que em regimes parlamentaristas. Em segundo lugar, no presidencialismo, o partido do presidenteé sempre o partido formador. Por fim, no presidencialismo, o governo permanece no poder mesmo que uma maioria deseje substituí-lo.

Visto que no parlamentarismo todas as coalizões ministeriais constituem coalizões parlamentares majoritárias, a questão central deste trabalho se reduz a saber por que os presidentes também não formam coalizões parlamentares majoritárias. A resposta está longe de ser evidente. Se as coalizões possíveis, o protocolo de barganha e os pontos de reversão fossem os mesmos nos dois sistemas, evidentemente, as mesmas coalizões se formariam. Mesmo que se reconheça que o partido do presidente, o qual chamaremos de $P$, deve fazer parte do governo, e ainda que se conceda um protocolo de barganha diferente, se os pontos de reversão fossem os mesmos, presidentes poderiam negociar ministérios em troca do apoio legislativo de um partido e construir uma maioria parlamentar em condições idênticas às do parlamentarismo. Portanto, a diferença deve estar no ponto de reversão.

Sob um ponto de reversão tal como definido por Austen-Smith e Banks, coalizões ministeriais seriam sempre formadas no presidencialismo. Nestas condições, a política é definida como $x^{*}$ e cada partido detém uma quota $g^{j}=\left(x^{*}-x^{j}\right)^{2}$ de ministérios. Considerando que qualquer desvio da política em relação ao ponto ideal de um partido lhe confere uma utilidade negativa, e como o partido $C$ não pode oferecer nenhum ministério ao partido $B$ - somente $P$ pode fazê-lo -, uma coalizão entre $B$ e $C$ não poderia ter para estes partidos um valor maior do que o do ponto de reversão. $O$ presidente, por sua vez, poderia oferecer mais a um destes partidos, e assim conquistar sua cooperação, simplesmente tirando ministérios de um e dando-os ao outro. O ponto de reversão de Kalandrakis somente é aplicável ao presidencialismo se o presidente for um independente cercado de especialistas sem ligação com partidos. Mas como neste caso todos os partidos recebem utilidades negativas, coalizões também sempre se formariam no presidencialismo. 
A única razão que podemos sugerir para explicar por que os presidentes nem sempre formam coalizões é a seguinte: em regimes parlamentaristas, sempre que uma maioria espera beneficiar-se da ocorrência de eleições antecipadas, eleições ocorrem quase que imediatamente; em regimes presidencialistas, no entanto, não existe alternativa, a não ser esperar a chegada da próxima eleição prevista no calendário eleitoral. O período de espera é desagradável para os partidos de oposição: enquanto aguardam, não usufruem nenhum ministério. Mas se outros partidos que não o do presidente acreditam que fazendo oposição podem ganhar vantagens eleitorais, então, estarão dispostos a esperar. Portanto, em regimes presidencialistas é possível ocorrer uma situação em que uma maioria de parlamentares se une contra o presidente enquanto o governo se mantém no poder.

Mas se a oposição tem motivos para se opor ao presidente, este pode ter o incentivo e os meios para induzi-la a cooperar. Para que possamos entender o que pode acontecer, é preciso, em primeiro lugar, identificar o ponto de reversão: se uma coalizão presidencial não se formar e a oposição não se unir contra o presidente, o partido do presidente ficará com todos os ministérios e fixará a política em seu ponto ideal através de negociações individuais com legisladores ou partidos.

Os resultados possíveis dependem da alocação de poderes legislati$\operatorname{vos}^{9}$. Se a oposição pode legislar - isto é, se ela pode apresentar propostas de lei e/ou derrubar vetos presidenciais -, o ponto de reversão jamais ocorrerá: os partidos que não o do presidente podem aceitar uma política $x_{B C}^{*}$, que é melhor para eles do que o ponto ideal do presidente, $x^{P}$. Assim, os resultados possíveis são ou uma oposição unida contra o presidente ou uma coalizão ministerial do presidente com o partido mais próximo no espaço político. Se existe a possibilidade de uma coalizão parlamentar de oposição estabelecer a política em um ponto distante do ponto ideal do presidente, $x_{B C}^{*}$ está longe de $x^{P}, \mathrm{o}$ presidente oferece ministérios para mover a política para um ponto mais próximo. Se uma coalizão majoritária oposicionista só puder se formar quando incluir um ou mais partidos próximos do presidente no espaço de políticas, este não terá incentivos para oferecer ministérios à oposição, preferindo deixá-la legislar.

Se a assembléia não pode tomar a iniciativa de apresentar projetos de lei, ou se o presidente pode vetar leis sem que seu veto seja derruba- 
do, o resultado pode ser a paralisia legislativa. Isto porque, neste caso, o presidente propõe leis e a oposição as rejeita, sem ser capaz de, ao mesmo tempo, fazer passar as suas próprias políticas. O resultado então é o status quo, o qual podemos denominar como $x^{*}{ }_{S Q}$. Note-se, aliás, que, contrariando outra afirmação muito difundida (Linz, 1978; 1994; Ackerman, 2000:645; Nino, 1996:168-169; Hartlyn, 1994:221; González e Gillespie, 1994:172), segundo a qual o fracasso na aprovação de leis exige mecanismos extraconstitucionais para romper o impasse, quase todas as Constituições presidencialistas estipulam o que deve acontecer nessa eventualidade ${ }^{10}$. E tal situação só ocorre em circunstâncias muito especiais: o presidente deve ter o controle efetivo da agenda, o status quo deve ser melhor para os partidos de oposição do que o ponto ideal do presidente e deve estar suficientemente próximo ao ponto ideal do presidente para que este prefira não implementar uma solução de compromisso. Em outras palavras, a paralisia legislativa só ocorre se nenhum partido de oposição preferir o ponto ideal do presidente ao status quo e se o presidente preferir o status quo a uma coalizão. Assim, por mais veementes que sejam os discursos, não passam de uma nuvem de fumaça que encobre um consenso subjacente. E quando o status quo for menos desejável, novamente, ou bem se constitui uma coalizão ministerial (nos casos em que a distância política é grande), ou bem um governo de minoria se depara com uma coalizão parlamentar majoritária próxima do presidente.

A diferença entre os dois sistemas, portanto, é que, enquanto no parlamentarismo o governo é dissolvido sempre que sua coalizão parlamentar perde a maioria, no presidencialismo, o governo sobrevive a despeito de seu tamanho parlamentar. No parlamentarismo, se existe uma maioria que acredita que possa se beneficiar com a antecipação das eleições, seus membros podem escolher entre extrair mais vantagens do governo e permanecer na coalizão, ou apostar em novas eleições. Assim, um governo de gabinete dura tanto quanto sua coalizão parlamentar. Já no presidencialismo, o Congresso não controla a ocorrência das eleições. Dessa forma, se os partidos não presidenciais acreditam ter boas chances nas próximas eleições, eles têm que aguardar até o momento de sua ocorrência. Enquanto isso, o governo sobrevive, ainda que, em situação semelhante no parlamentarismo, ele teria sido derrubado.

A análise até aqui desenvolvida se baseia na suposição de que só existem três partidos no Legislativo. Como fica, então, a afirmação de que 
coalizões presidenciais são particularmente difíceis de ser formar quando o Legislativo é mais fragmentado? O que se pode dizer é que o efeito de um aumento no número de partidos é indeterminado, a não ser que se conheça a distribuição de suas preferências políticas.

Proposição 3. Se uma maior fragmentação partidária torna mais (menos) provável a emergência de Assembléias com pontos ideais de politica distantes do ponto do partido formador, coalizões ministeriais serão mais (menos) prováveis quando o número de partidos for grande (ver demonstração na última seção).

Para se saber o que está por trás desta proposição, considere o seguinte exemplo. Suponha-se que em uma Assembléia de três partidos, um deles esteja mais perto do ponto ideal de políticas do presidente, de modo que não se forme uma coalizão ministerial. Suponha-se, agora, que o partido mais próximo do presidente se divida em duas alas, uma a favor e outra contra o presidente, de forma que uma coalizão parlamentar contra o presidente seja majoritária. Nessas condições, para que possa trazer a política para um ponto mais próximo ao seu ideal, o presidente tem incentivos para oferecer ministérios aos partidos antigovernistas.

\section{CONSEQÜÊNCIAS PARA A EFICÁCIA LEGISLATIVA}

Nossa análise gera conseqüências empíricas surpreendentes em relação à eficácia legislativa do Executivo.

Proposição 4. Coalizões ministeriais formam-se quando a distância política entre o partido formador e o partido dele mais próximo é relativamente grande. Quando um governo é minoritário, a política está relativamente mais próxima de seu ponto ideal.

A perda de utilidade marginal associada à perda de pastas ministeriais é constante, enquanto a perda de utilidade marginal decorrente do aumento da distância entre o ponto ideal do partido e a política adotada aumenta nessa mesma distância. Considere o Gráfico 1. A perda marginal decorrente da privação de ministérios é -1, enquanto a perda marginal relativa ao aumento da distância da política é $-2\left(x^{j}-x^{*}\right)$. Portanto, se o partido formador estiver relativamente perto, em termos de política, do partido a ele mais próximo, o partido formador vai preferir manter os ministérios e abrir mão de uma parte da política. Mas quando é grande a distância política em relação ao parti- 
do mais próximo, o partido formador prefere desistir dos ministérios a abrir mão da política. Visto que as coalizões ministeriais só se formam se o formador e o partido mais próximo estiverem longe um do outro em termos de política, a conclusão principal a que se chega é que a distância entre a política escolhida por governos de coalizão e o ponto ideal do formador é maior do que a distância entre o ponto ideal do governo de partido único e do partido a ele mais próximo. Por essa razão, paradoxalmente, as coalizões ministeriais estão quase explodindo nas fronteiras do espaço político, enquanto os governos minoritários experimentam uma tranqüila navegação legislativa. Isto é verdade tanto para regimes parlamentaristas quanto para regimes presidencialistas.

\section{Gráfico 1}

Custos Marginais das Coalizões

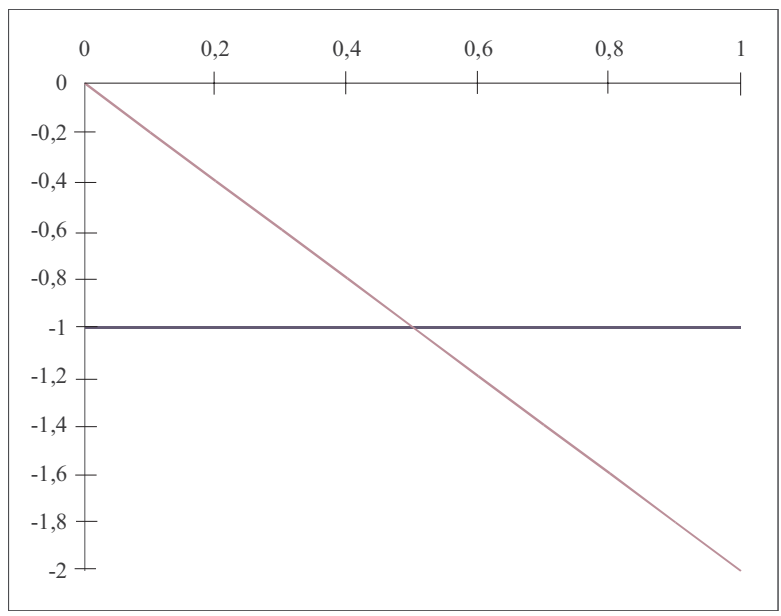

O que nos parece surpreendente é a implicação de que governos de minoria não são menos eficazes do ponto de vista legislativo do que coalizões majoritárias. Note-se que desde o livro seminal de Strom (1990), é esta a visão consensual sobre o parlamentarismo. No entanto, essa conclusão se choca contra o discurso acerca do "governo dividido". O nosso modelo, a favor de Mayhew (1991) e contra Sundquist (1989), implica (1) pouca diferença em termos de políticas entre governos unidos e governos divididos, e (2) níveis similares de eficácia legislativa entre governos minoritários e de coalizão. Por conseguinte, mesmo partindo de hipóteses diferentes, chegamos à mesma conclusão de Laver e Shepsle (1991), segundo os quais "governos dividi- 
dos", no sentido norte-americano, são análogos aos governos minoritários no parlamentarismo.

\section{TESTES EMPÍRICOS}

Para que possamos interpretar os padrões observados, consideremos, em primeiro lugar, as diferentes situações possíveis. Um único partido pode conquistar uma maioria de cadeiras no Legislativo. Quando isto acontece, esse partido pode formar o governo sozinho (UNIMAJ) ou compor uma coalizão supermajoritária (SUPERMAJ). Mas também é possível que o partido majoritário não participe do governo (DIVIDIDO). Quando nenhum partido obtém maioria, pode-se constituir uma coalizão ministerial e essa coalizão pode (COALMAJ) ou não (COALMIN) controlar em conjunto uma maioria de cadeiras do Parlamento. Finalmente, quando nenhum partido sozinho obtém a maioria das cadeiras e nenhuma coalizão ministerial é formada, o governo é uma minoria de um único partido (UNIMIN). Com esta classificação, podemos, assim como o leitor, calcular as probabilidades condicionais que nos interessam, especificamente a probabilidade de que se constitua uma coalizão quando nenhum partido detém a maioria, a probabilidade de que uma coalizão formada nessas condições seja majoritária e a probabilidade de que um governo seja uma minoria. Observe-se que o governo terá o controle de uma maioria de cadeiras se for UnIMAJ, SUPERMAJ ou COALMAJ. Por outro lado, o governo é de minoria se for DIVIDIDO, COALMIN ou UNIMIN.

Diferentes maneiras de condicionar esses padrões fornecem informações distintas. O número total de partidos no Parlamento (NTOTP) determina as possibilidades lógicas. Se há somente dois partidos, salvo no caso de empate, um deles deve ter maioria. Neste caso, ou bem o partido majoritário governa sozinho ou bem ele forma uma grande coalizão. No presidencialismo, porém, é também possível que o partido majoritário faça oposição ao presidente, fenômeno que, em sistemas de dois partidos, só ocorre nos Estados Unidos. Se existem três partidos, todas as coalizões serão majoritárias. Se for quatro ou mais o número de partidos, todas as possibilidades descritas acima se tornam possíveis. A Tabela 1 apresenta as freqüências com que observamos essas diferentes alternativas ${ }^{11}$. Nesta tabela, assim como no restante deste trabalho, distinguimos sistemas "mistos" ou "semipresidencialistas" apenas para destacar os casos de parlamentarismo puro 
e de presidencialismo puro. Os sistemas mistos são em si mesmos um tema de estudo, e não nos referiremos a eles aqui.

Tabela 1

Tipos de Governo como Função do Número de Partidos

\begin{tabular}{|c|c|c|c|c|}
\hline Nтотр & Governos & Parlamentarismo & Misto & Presidencialismo \\
\hline \multirow[t]{8}{*}{ Todos } & SUPERMAJ & 0,0439 & 0,1039 & 0,0754 \\
\hline & UNIMAJ & 0,4380 & 0,1792 & 0,4031 \\
\hline & Dividido & 0,0000 & 0,0000 & 0,0723 \\
\hline & CoAlmaj & 0,0384 & 0,5806 & 0,1338 \\
\hline & COALMin & 0,0802 & 0,0645 & 0,1031 \\
\hline & UNIMIN & 0,1295 & 0,0717 & 0,2123 \\
\hline & Nтотр & 5,48 & 7,28 & 6,09 \\
\hline & $\mathrm{N}$ & 1459 & 279 & 650 \\
\hline \multirow[t]{4}{*}{2} & SUPERMAJ & 0,0272 & - & 0,0000 \\
\hline & UNIMAJ & 0,9728 & - & 0,6981 \\
\hline & Dividido & 0,0000 & - & 0,3019 \\
\hline & $\mathrm{N}$ & 257 & 0 & 106 \\
\hline \multirow[t]{6}{*}{3} & SUPERMAJ & 0,0528 & 0,0000 & 0,0824 \\
\hline & UnIMAJ & 0,5691 & 1,0000 & 0,5176 \\
\hline & Dividido & 0,0000 & 0,0000 & 0,1882 \\
\hline & Coalmaj & 0,2846 & 0,0000 & 0,0235 \\
\hline & UNIMIN & 0,0636 & 0,0000 & 0,1883 \\
\hline & $\mathrm{N}$ & 246 & 6 & 85 \\
\hline \multirow[t]{7}{*}{$\geq 4$} & SUPERMAJ & 0,0460 & 0,1062 & 0,0915 \\
\hline & UNIMAJ & 0,2605 & 0,1612 & 0,3137 \\
\hline & Dividido & 0,0000 & 0,0000 & 0,0000 \\
\hline & Coalmaj & 0,3975 & 0,5934 & 0,1852 \\
\hline & CoAlmin & 0,1224 & 0,0659 & 0,1460 \\
\hline & UNIMIN & 0,1736 & 0,0733 & 0,2636 \\
\hline & $\mathrm{N}$ & 956 & 273 & 459 \\
\hline
\end{tabular}

Note-se, em primeiro lugar, que embora o número total de partidos seja um pouco maior sob o presidencialismo, maiorias de partido único existem nos regimes presidencialistas em $55,1 \%$ dos casos contra $48,2 \%$ nos regimes parlamentaristas.

Quando nenhum partido obtém maioria (COALMAJ + COALMIN + UNIMIN), as coalizões (COALMAJ + COALMIN) emergem em 75\% dos ca- 
sos no parlamentarismo, 79\% delas (COALMAJ) são majoritárias. No presidencialismo, elas emergem em 53\% dos casos, com 57\% delas majoritárias. Nesse sentido, quando não existe um partido majoritário, os sistemas parlamentaristas são regidos por um governo de minoria em $40 \%$ dos casos, e $70 \%$ nos regimes presidencialistas.

A diferença mais marcante entre os dois sistemas ocorre quando nenhum partido obtém maioria em um parlamento de três partidos. Nestes casos, as coalizões emergem em $82 \%$ dos casos no parlamentarismo e em apenas $11 \%$ no presidencialismo. Como essas coalizões são majoritárias, sistemas parlamentaristas com um Legislativo com três partidos são regidos por governos majoritários em $94 \%$ dos casos e sistemas presidencialistas na mesma situação em $62 \%$. Observe-se, porém, que parlamentos de três partidos são raros: só ocorrem em $13 \%$ dos casos.

Quando o número de partidos é de quatro ou mais, e nenhum deles detém a maioria, as coalizões emergem em $75 \%$ dos casos no parlamentarismo, e $76 \%$ delas são majoritárias. No presidencialismo, as coalizões ocorrem em $56 \%$ dos casos, com $56 \%$ destas sendo majoritárias. Portanto, nestas circunstâncias, formam-se coalizões majoritárias em $57 \%$ dos casos sob parlamentarismo e em $31 \%$ sob presidencialismo. Ademais, ainda que não apresentado na tabela, deve-se dizer que as coalizões, mesmo as majoritárias, são mais freqüentes nos parlamentos que possuem oito ou mais partidos do que nos que possuem de quatro a sete partidos.

Outra forma de observar esses padrões é condicionar os resultados à proporção de cadeiras controladas pelo maior partido (MAIORPART). Cabe notar, antes de examinarmos a Tabela 2, que, no parlamentarismo, o primeiro-ministro pertence ao maior partido em $86 \%$ dos casos, o que mostra que a suposição de que o maior partido é o partido formador faz sentido. No presidencialismo, o presidente é o formador, seja qual for o tamanho do seu partido. Note-se, porém, que, em $75 \%$ dos casos, ele também pertence ao maior partido.

Quando o maior partido controla a maioria das cadeiras, há três possibilidades de governo: o partido majoritário governa sozinho, o partido majoritário governa em coligação, ou um partido minoritário forma o governo. A Turquia, em 1971-72, é o único exemplo de parlamentarismo em que um partido majoritário não deteve o cargo de pri- 
Tabela 2

Possibilidades de Governo como Função da Quota do Maior Partido no Congresso

\begin{tabular}{|c|c|c|c|c|}
\hline $\begin{array}{l}\text { Maior Partido } \\
\text { (MP) }\end{array}$ & Governos & Parlamentarismo & Misto & Presidencialismo \\
\hline \multirow[t]{8}{*}{ Todos } & SUPERMAJ & 0,0427 & 0,1039 & 0,0742 \\
\hline & UNIMAJ & 0,4490 & 0,1792 & 0,4000 \\
\hline & Dividido & 0,0000 & 0,0000 & 0,0712 \\
\hline & COALMAJ & 0,3009 & 0,5806 & 0,1318 \\
\hline & COALMin & 0,0781 & 0,0645 & 0,1015 \\
\hline & UnIMIN & 0,1294 & 0,0717 & 0,2212 \\
\hline & Nтотр & 5,48 & 7,28 & 6,09 \\
\hline & $\mathrm{N}$ & 1499 & 279 & 660 \\
\hline \multirow[t]{4}{*}{$\mathrm{MP}>0,5$} & SUPERMAJ & 0,0868 & 0,3671 & 0,1361 \\
\hline & UNIMAJ & 0,9132 & 0,6329 & 0,7333 \\
\hline & Dividido & 0,0000 & 0,0000 & 0,1306 \\
\hline & $\mathrm{N}$ & 737 & 79 & 360 \\
\hline \multirow[t]{4}{*}{$\mathrm{MP} \leq 0,5$} & Coalmaj & 0,5919 & 0,8100 & 0,2900 \\
\hline & COALMin & 0,1535 & 0,0900 & 0,2233 \\
\hline & UNIMIN & 0,2546 & 0,1000 & 0,4867 \\
\hline & $\mathrm{N}$ & 762 & 200 & 300 \\
\hline \multirow[t]{4}{*}{$0,33<\mathrm{MP} \leq 0,5$} & COALMAJ & 0,5652 & 0,7984 & 0,2791 \\
\hline & Coalmin & 0,1320 & 0,0968 & 0,1581 \\
\hline & UNIMIN & 0,3027 & 0,1048 & 0,5628 \\
\hline & $\mathrm{N}$ & 621 & 124 & 215 \\
\hline \multirow[t]{4}{*}{$\mathrm{MP} \leq 0,33$} & Coalmaj & 0,7092 & 0,8289 & 0,3176 \\
\hline & COALMIN & 0,2482 & 0,0785 & 0,3882 \\
\hline & UnIMIN & 0,0426 & 0,0921 & 0,2941 \\
\hline & $\mathrm{N}$ & 141 & 76 & 85 \\
\hline
\end{tabular}

meiro-ministro. Governos divididos, nos quais o partido majoritário não faz parte do governo, somente acontecem nos sistemas presidencialistas. É predominantemente um fenômeno americano, ainda que tenha também existido na Costa Rica entre 1966 e 1969, na República Dominicana em 1998-99, El Salvador em 1988 e nas Filipinas entre 1961 e 1964. 
Nos regimes parlamentaristas, o governo é de coalizão em $75 \%$ das vezes em que nenhum partido controla a maioria das cadeiras legislativas; destas, 79\% são coalizões majoritárias, o que significa que o governo é de minoria em $41 \%$ dos casos. Em circunstâncias idênticas, ou seja, quando não existe partido majoritário, há um governo de coalizão em 51\% dos casos de regimes presidencialistas, 56\% dos quais majoritários, de modo que governos de minoria ocorrem em $71 \%$ dos casos.

Por fim, a elevada fragmentação favorece a formação de coalizões. Quando o maior partido detém entre um terço e a metade das cadeiras nos sistemas parlamentaristas, coalizões emergem em $70 \%$ dos casos, $81 \%$ delas majoritárias, e o governo controla a maioria das cadeiras em $57 \%$ dos casos. Quando o maior partido controla menos de um terço das cadeiras em sistemas parlamentaristas, coalizões formamse em $96 \%$ dos casos, $74 \%$ delas alcançam maioria, e o governo é majoritário em $71 \%$ dos casos. Essa diferença é ainda maior em sistemas presidencialistas. Quando o maior partido controla entre um terço e metade das cadeiras nestes sistemas, há coalizões em $44 \%$ dos casos, $64 \%$ dessas coalizões são majoritárias e o governo tem maioria em $28 \%$ dos casos. Quando o principal partido é pequeno, há governos de coalizão em $70 \%$ dos casos, $45 \%$ dos quais alcançam maioria e o governo é majoritário em $32 \%$ dos casos. Portanto, em ambos os sistemas, coalizões ministeriais ocorrem com mais freqüência quando o Legislativo é mais fragmentado. Ademais, embora o maior partido seja pequeno, a probabilidade de as coalizões atingirem a maioria é maior quando o Legislativo é mais fragmentado.

Portanto, a maior diferença entre os dois sistemas se dá quando existem três partidos legislativos ou quando o maior partido detém entre um terço e metade das cadeiras; sob estas condições, as coalizões são muito menos freqüentes no presidencialismo. A explicação sugerida por nosso modelo é que, havendo maior número de partidos, aumenta a probabilidade de uma coalizão legislativa escolher uma política mais distante do ponto ideal do formador. O formador, com o fim de evitar esta eventualidade, torna-se mais propenso a sacrificar ministérios para obter uma política mais próxima de sua preferência. Outra explicação plausível é que quando o partido formador controla um número de cadeiras próximo da maioria, ele pode usar a indisciplina da oposição em determinadas questões políticas para alcançar a maioria sem ter que sacrificar ministérios. Uma outra explicação é que, 
havendo apenas três partidos, cada um deles tem chances razoáveis de ganhar o grande prêmio de tornar-se o formador na próxima eleição, seja conquistando a maioria das cadeiras ou a Presidência. Assumindo-se que a Presidência seja um prêmio maior do que a maioria no parlamentarismo (Linz, 1994:18), o incentivo para que os partidos não presidenciais se oponham ao presidente e aguardem a próxima eleição é particularmente elevado.

Para que possamos sair dessa floresta de números, consideremos o que é essencial. Enquanto governos minoritários são mais freqüentes sob o presidencialismo, em ambos os sistemas a maior parte dos governos são majoritários. Quando consideramos todos os anos, inclusive aqueles em que um partido controla sozinho a maioria das cadeiras, vemos que governos de minoria existem em 39\% dos casos sob presidencialismo e $21 \%$ sob parlamentarismo. Há uma diferença entre os dois sistemas. Mas esta diferença é de grau, não de espécie.

A verdade é que quando outros partidos não toleram um governo de minoria no parlamentarismo, a situação se resolve nas urnas, ao passo que, no presidencialismo, o governo sobrevive mesmo quando não é tolerado. Se a lógica da formação de coalizões é a mesma nos dois sistemas - e, na nossa opinião, demonstramos que de fato é -, o que devemos observar é que, dependendo da distribuição das cadeiras no Parlamento e das preferências políticas, a freqüência de governos de minoria no presidencialismo é igual à soma da freqüência de governos minoritários e eleições antecipadas no parlamentarismo. Em outras palavras, a diferença entre o número de governos minoritários nos dois sistemas deve ser igual à freqüência de eleições antecipadas no parlamentarismo ${ }^{12}$. De fato, eleições antecipadas ocorreram em $11 \%$ dos casos nestes regimes. O que nos leva a concluir que: (1) como todo mundo sabe, o parlamentarismo tem uma válvula de escape que não se encontra disponível sob o presidencialismo, da qual faz uso em $11 \%$ do tempo; mas (2) fora isto, os dois sistemas mais ou menos se equivalem em sua capacidade de gerar governos majoritários: $61 \%$ das vezes no presidencialismo e $68 \%(100-21$ - 11) no parlamentarismo; ao passo que (3) a diferença restante deve decorrer da distribuição de preferências políticas nos dois sistemas.

Por fim, cabe perguntar: o que isto importa? A ênfase na formação de coalizões baseia-se no pressuposto de que governos de minoria são ineficazes do ponto de vista legislativo, o que produz uma série de 
conseqüências deletérias. Porém, aprendemos com Strom (1990) que os governos minoritários representam um padrão normal de vida política em alguns sistemas parlamentaristas e que estes não geram desastres políticos. De fato, Beyme (2000:177) observou que "os sistemas parlamentaristas escandinavos, nos quais são freqüentes os governos de minoria, não são menos eficientes do que outros sistemas. Não fosse assim, esses países não estariam no topo em termos de bem-estar e estilo de vida liberal". Com base em que, então, se pensa que governos de minoria constituem uma calamidade no presidencialismo?

De acordo com as suposições do modelo que apresentamos acima, um governo parlamentarista nunca deveria sofrer derrotas legislativas, a não ser que fossem seguidas por novas eleições. Na prática, os governos parlamentaristas sofrem várias derrotas legislativas sem que isto leve à sua derrubada. Isto se deve ao fato de que em alguns sistemas parlamentaristas existe uma "folga" entre derrotas do governo em votações específicas e a derrubada do governo por meio de uma derrota legislativa. Essa folga existe, por exemplo, quando (1) a oposição só pode aprovar um voto de desconfiança no governo se simultaneamente aprovar um novo governo (o "voto construtivo de desconfiança" que existe na Alemanha); (2) o Parlamento controla a agenda legislativa por intermédio de comissões e simplesmente decide não deliberar sobre os projetos do governo (Itália, Portugal); (3) o governo e a oposição decidem em comum acordo que o governo não legisla (Dinamarca entre 1982 e 1988). Nessas circunstâncias, derrotas legislativas não provocam a queda do governo, de modo que a oposição pode preferir manter o governo e, ao mesmo tempo, derrotá-lo em matérias específicas. A única diferença em relação ao presidencialismo é que nele a oposição não pode destituir o governo, ainda que queira fazê-lo. Portanto, um governo presidencialista pode ser derrotado no Legislativo em circunstâncias que, em regimes parlamentaristas, levariam à formação de um novo governo. Mas como estas situações são bastante raras - dadas as lógicas idênticas, a freqüência de tais situações corresponde à freqüência com que se realizam eleições antecipadas no parlamentarismo -, a expectativa é que os governos parlamentaristas sejam apenas ligeiramente mais eficazes do que os governos presidencialistas. Por conseguinte, o que se deve observar é que, em ambos os sistemas, os governos são consideravelmente eficazes na aprovação de suas iniciativas pelo Legislativo, e que os governos 
parlamentaristas são apenas levemente mais eficazes do que os presidencialistas.

Com base nos dados coletados por Saiegh (2001), podemos fazer um primeiro exame de uma conseqüência central de nossa análise, isto é, que os governos minoritários de partido único não são necessariamente menos eficazes do ponto de vista legislativo do que os governos de coalizão. Usamos como indicador de eficácia legislativa a proporção dos projetos de lei do Executivo que são aprovados pelo Legislativo. Pelo menos nesse banco de dados, ainda a ser completado e apurado $^{13}$, os resultados confirmam as expectativas teóricas. Governos minoritários de um único partido não geram crises legislativas: $81,3 \%$ de seus projetos são aprovados nos sistemas parlamentaristas e $65,2 \%$ nos presidencialistas ${ }^{14}$. Além disso, ao contrário do que geralmente se pensa, nos dois sistemas os governos de coalizão, majoritários ou minoritários, não são mais eficazes do ponto de vista legislativo do que os governos minoritários de um único partido.

Tabela 3

Eficiência Legislativa do Executivo como Função da Situação de Governo

\begin{tabular}{l|c|c|c}
\hline Situação & Parlamentarismo & Misto & Presidencialismo \\
\hline TODOS & $82,8(275)$ & $76,0(54)$ & $64,1(189)$ \\
SUPERMAJ & $89,6(13)$ & $86,1(8)$ & $82,6(9)$ \\
UNIMAJ & $89,5(103)$ & $91,2(8)$ & $77,4(43)$ \\
COALMAJ & $76,0(105)$ & $75,7(30)$ & $47,5(33)$ \\
COALMIN & $81,7(20)$ & $58,1(3)$ & $52,5(24)$ \\
UNIMIN & $81,3(34)$ & $47,8(5)$ & $65,2(80)$ \\
\hline
\end{tabular}

Nota: Governos divididos foram agrupados em UnIMAJ.

Obs.: № de observações entre parênteses.

Portanto, a motivação para o interesse na formação de coalizões parece estar equivocada. Governos de minoria não resultam de "fracassos" do processo de formação de alianças. Quando o partido do presidente está politicamente próximo de um partido ou partidos com o qual ele constitui uma maioria parlamentar, governos de minoria legislam de maneira tão eficaz quanto governos de coalizão majoritária. Governos de minoria emergem pois é isto o que todos os atores querem: o partido do presidente não sacrifica ministérios, enquanto os outros partidos podem dizer que se "opõem" ao presidente mesmo apoiando medidas próximas às preferências do presidente. Não se produz nenhum desastre parlamentar. 
E também não se produzem catástrofes. As democracias presidencialistas são mais frágeis do que as parlamentaristas ou mistas. Sua expectativa de vida é de cerca de vinte anos, enquanto a de uma democracia parlamentarista é de 69 anos. Mas a razão desta diferença não se deve à inabilidade das democracias presidencialistas para formar coalizões. Na verdade, a probabilidade de uma democracia presidencialista morrer é a mesma seja o governo de coalizão ou não, e quase a mesma seja o governo de maioria ou não. O fato é que as democracias presidencialistas simplesmente morrem com muito mais freqüência do que as democracias parlamentaristas, sejam quais forem as circunstâncias. Portanto, o que torna as democracias presidencialistas mais vulneráveis tem pouco a ver com o processo de formação de coalizões.

Tabela 4

Probabilidade de Morte de Regimes Democráticos como Função da Situação de Governo

\begin{tabular}{l|c|c|c}
\hline Situação & Parlamentarismo & Misto & Presidencialismo \\
\hline TODOS & 0,0145 & 0,0115 & 0,0502 \\
SUPERMAJ & 0,0164 & 0,0000 & 0,0208 \\
UNIMAJ & 0,0137 & 0,0417 & 0,0584 \\
COALMAJ & 0,0092 & 0,0000 & 0,0723 \\
COALMIN & 0,0180 & 0,0556 & 0,0469 \\
UNIMIN & 0,0263 & 0,0000 & 0,0378 \\
COALIZÕES & 0,0116 & 0,0051 & 0,0513 \\
UM PARTIDO & 0,0165 & 0,0303 & 0,0498 \\
MAIORIA & 0,0122 & 0,0088 & 0,0567 \\
MINORIA & 0,0233 & 0,0278 & 0,0402 \\
\hline
\end{tabular}

Nota: Governos divididos foram agrupados em UnIMAJ.

\section{DEMONSTRAÇÕES}

\section{- Demonstração da Proposição 2}

Considere uma assembléia de três partidos, $j \varepsilon\{P, B, C\}$, onde $P$ representa o partido do presidente. A única suposição que se faz a respeito do tamanho parlamentar destes partidos é que nenhum deles controla a maioria das cadeiras. Por convenção, o partido $B$ está mais perto 
de $P$ em termos de preferências políticas, de modo que $x^{C}>x^{B}>x^{P}$ (ou vice-versa). $O$ valor de $G$ é alto.

Para comparar os resultados nos dois sistemas, temos de examinar primeiro os pontos de reversão. No parlamentarismo, o ponto de reversão é uma eleição instantânea; no presidencialismo, porém, uma eleição instantânea só ocorre quando o presidente pode dissolver o Congresso. Mas como isto é extremamente raro, analisamos os sistemas presidencialistas em que a ocorrência de eleições é regida pelo calendário eleitoral preestabelecido.

Qual é, então, o ponto de reversão no presidencialismo? É razoável supor que se os partidos não presidenciais não formarem uma coalizão parlamentar majoritária, o presidente será capaz de aprovar as leis de seu interesse, seja com base nos votos favoráveis ou abstenção de um dos dois partidos, seja usando o seu controle sobre a agenda. Dessa maneira, os valores do ponto de reversão são:

$$
\begin{gathered}
U^{P}=G \\
U^{B}=-\left(x^{P}-x^{B}\right)^{2} \\
U^{C}=-\left(x^{P}-x^{C}\right)^{2}
\end{gathered}
$$

Note-se que este resultado corresponde à situação ideal para o partido do presidente.

No presidencialismo, não faz sentido pensar em uma seqüência de ofertas entre $B$ e $C$, os quais enfrentam um problema de barganha cooperativa caso o presidente não consiga induzi-los a participar de uma coalizão. Além disso, o leque de possibilidades sobre o que $B$ e $C$ podem acordar entre eles depende dos poderes de agenda do presidente. Os sistemas presidencialistas variam significativamente no que diz respeito às prerrogativas do presidente de propor e vetar projetos legislativos. Em um extremo encontra-se o sistema americano, em que o presidente não tem poder formal de propor leis. Na maioria dos sistemas presidencialistas, o presidente pode encaminhar ao Congresso qualquer tipo de legislação. No extremo oposto encontra-se o sistema presidencialista no qual somente o presidente pode propor o orçamento. Essas diferenças, junto com o poder de veto, criam duas situações genéricas: 
(1) se o Parlamento tem iniciativa sobre projetos significativos e o presidente não tem, de facto ou de jure, poder de veto, os partidos não presidenciais podem formar uma coalizão parlamentar $\{C B\}$ com a política definida em um ponto $x_{C B}^{*}$, de modo que:

$$
x^{B} \leq x^{*}{ }_{C B} \leq x^{C}
$$

e uma alocação ministerial

$$
\begin{aligned}
& g^{C}=0 \\
& g^{B}=0 \\
& g^{P}=G
\end{aligned}
$$

Suponhamos que se os partidos não presidenciais formarem uma coalizão contra o presidente, eles recebam na eleição seguinte uma utilidade com o valor corrente $V^{k}>0$, e que, caso esta coalizão não se forme, cada um receba $V^{k}=0, k \varepsilon B, C$. Assim, as utilidades dos partidos nesse estágio serão:

$$
\begin{gathered}
U^{P}=G-\left(x_{C B}^{*}-x^{P}\right)^{2} \\
U^{B}=-\left(x_{C B}^{*}-x^{B}\right)^{2}+V^{B} \\
U^{C}=-\left(x_{C B}^{*}-x^{C}\right)^{2}+V^{C}
\end{gathered}
$$

Logo, se no primeiro estágio o presidente não conseguir formar uma coalizão com um dos partidos, uma coalizão parlamentar majoritária lhe fará oposição. O resultado de reversão jamais será atingido.

Considere agora o problema do presidente. O presidente pondera a possibilidade de fazer uma oferta que induza um dos partidos a entrar em uma coalizão ministerial e/ ou parlamentar. Ele raciocina da seguinte maneira. Se não formar uma coalizão parlamentar, $B$ e $C$ unir-se-ão para formá-la. O máximo que $C$ pode dar a $B$ é $x_{C B}^{*}=x^{B}$. Por conseguinte, para impedir uma coalizão antipresidencial, o presidente tem de dar a $B$ no mínimo a mesma utilidade, qual seja, $V^{B}$. Dessa maneira, o problema do presidente é:

$\max g^{P}-\left(x-x^{P}\right)^{2}$

sujeito a

$G-g^{P}-\left(x-x^{B}\right)^{2} \geq V^{B}$ 
A solução é15

$x^{*}{ }_{P B}=x^{P}+x^{B} / 2$

$g^{P}=G-\left(x_{P B}^{*}-x^{B}\right)^{2}-V^{B}$

$g^{B}=\left(x_{P B}^{*}-x^{B}\right)^{2}+V^{B}$

com as utilidades

$U^{P}=G-2\left(x_{P B}^{*}-x^{P}\right)^{2}-V^{B}$

$U^{B}=V^{B}$

$U^{C}=-\left(x_{P B}^{*}-x^{C}\right)^{2}$

Mas é preciso conferir se o presidente vai querer fazer esta oferta, isto é, se

$G-2\left(x_{P B}^{*}-x^{P}\right)^{2}-V^{B} \geq G-\left(x^{B}-x^{P}\right)^{2}$

Portanto, o presidente não conseguirá formar uma coalizão ministerial, e uma coalizão parlamentar de oposição será formada se $V^{B}>1 / 2\left(x^{P}-x^{B}\right)^{2}$

Do contrário, uma coalizão majoritária ministerial-parlamentar será formada.

Essa condição diz respeito à relação entre a distância política que separa o partido do presidente e o partido dele mais próximo, assim como às perspectivas eleitorais do último. Se a distância entre os dois partidos for pequena, e o partido não presidencial tiver boas chances eleitorais, o presidente prefere manter todos os ministérios e tolerar uma política que resulte da negociação entre os dois outros partidos. No entanto, se nenhum outro partido estiver próximo do partido do presidente, o custo, em termos de política, de enfrentar uma maioria parlamentar de oposição torna-se alto demais, levando o presidente a preferir sacrificar pastas ministeriais para trazer a política para um ponto mais próximo de suas preferências.

(2) se o presidente tem o monopólio da iniciativa legislativa em questões de relevo (ou se o presidente tem, de facto e de jure, o poder de veto quando o Congresso pode iniciar legislação), ele faz uma proposta de lei que pode ser aprovada ou rejeitada pelo Congresso ${ }^{16}$. Tudo o que 
os partidos não presidenciais podem obter aliando-se contra o governo é um status quo, $x_{S Q}$, o qual varia conforme os diferentes sistemas presidencialistas e áreas substantivas de políticas. Se o status quo, seja ele qual for, for pior para pelo menos um dos partidos do que a política ideal do presidente, os partidos não presidenciais não se unirão contra o presidente; e, posto que a melhor situação para o presidente é o resultado de reversão, o presidente não faz oferta de coalizão. Nesse sentido, o ponto de reversão ocorre: o partido do presidente fica com todos os ministérios e fixa a política em seu ponto ideal. Se ambos os partidos preferirem o status quo ao ponto ideal do presidente e o status quo estiver próximo ao ponto ideal do presidente, o status quo prevalece. Se os dois partidos preferirem o status quo ao ponto ideal do presidente e o status quo estiver distante do ponto ideal do presidente, este oferece ministérios com o intuito de formar um governo de coalizão e a oferta é aceita. Por conseguinte, "paralisia legislativa" - uma situação em que o presidente faz propostas sabendo que serão rejeitadas e estas são de fato rejeitadas - só ocorre quando todos os atores optam pelo status quo.

\section{- Demonstração da Proposição 3}

Padronize a linha de políticas de modo que $x \varepsilon(0,1), \operatorname{com} x^{P}=1$. O Legislativo, composto de $j \varepsilon J$ partidos, tem 100 cadeiras. O número de cadeiras ocupadas pelo partido $j$ é $S^{j}$.

Consideremos, em primeiro lugar, um Legislativo composto de três partidos, cada um com a seguinte distribuição de cadeiras: $S^{P}=40$, $S^{B}=30, S^{C}=30$. Suponhamos que novos partidos sejam gerados através do seguinte processo:

(1) cada novo partido se coloca exatamente no meio da maior distância em termos de política entre dois partidos adjacentes (se os dois intervalos são iguais, um partido surge com chance de 50\%), de modo que $x^{\mathrm{J}+1}=\max _{j, k \varepsilon J}\left|x^{j}-x^{k}\right| / 2$. A suposição é que, quando o sistema partidário tem poucas barreiras à entrada, os partidos preenchem o espaço político;

(2) cada novo partido toma $\sum_{j \in J} S^{j}\left(1-\left|x^{J+1}-x^{j}\right|\right) / J$ dos partidos existentes. A suposição neste caso é que os novos partidos dividem os eleitores com os partidos que estão mais próximos deles no espaço político. 
Para que possamos aplicar essas regras a algumas assembléias hipotéticas, assumamos que o valor de se opor ao presidente seja $V=0,1$ para todos os partidos. Consideremos, em primeiro lugar, uma assembléia de três partidos em que $x^{B}=0,2$. Como o partido-pivô está longe do presidente, $0,1<0,5\left(x^{P}-x^{B}\right)^{2}$, forma-se uma coalizão ministerial. Surge, então, um novo partido, $P B$, na metade do intervalo $\left(x^{P}, x^{B}\right)$ de forma que o seu ponto ideal é $x^{P B}=0,6$. Este partido rouba cadeiras dos outros partidos em função das respectivas distâncias políticas, e a distribuição de cadeiras na assembléia em que $J=4$ é $S^{P}=32, S^{P B}=18$, $S^{B}=24, S^{C}=26$. Como o presidente ainda não tem maioria sem $B$, forma-se uma coalizão ministerial. Posta esta nova configuração $x^{P}-x^{P B}$ $=x^{P B}-x^{B}$, o quinto partido se coloca na metade de um desses intervalos. Suponhamos que ele se situe entre $x^{P}$ e $x^{P B}$, com um ponto ideal em $x^{P P B}=0,8$. A distribuição de cadeiras na nova assembléia com $J=5$ é, então, $S^{P}=25,6, S^{P P B}=15,5, S^{P B}=12,6, S^{B}=21,6, S^{C}=24,7$. Visto que $P B$ é agora o partido-pivô e está próximo do presidente, dado o valor de se opor ao presidente, uma coalizão ministerial não se forma, e o partido do presidente constitui um governo de minoria. Neste caso, portanto, o aumento da fragmentação partidária torna a formação de uma coalizão ministerial menos provável.

Consideremos, porém, uma assembléia de três partidos na qual $B$ esteja próximo do presidente, $x^{B}=0,8$. Se repetirmos os passos anteriores, veremos que não há formação de coalizões ministeriais nas assembléias de três e quatro partidos. Mas se o quinto partido for $B C C$, então o partido-pivô na assembléia com $J=5$ será $B C, \operatorname{com} x^{B C}=0,4$, e este partido estará suficientemente afastado do partido do presidente para que uma coalizão ministerial se forme. Portanto, neste caso a fragmentação favorece a formação de uma coalizão ministerial.

(Recebido para publicação em março de 2002) 


\section{NOTAS}

1. Nossa definição de democracia é a mesma empregada por Przeworski et alii (2000). Os dados utilizados neste trabalho foram originalmente coletados pelos autores e podem ser obtidos sob demanda. Aqui nós excluímos os casos em que as coalizões eram obrigatórias em virtude de um acordo pré-eleitoral entre os partidos (entre estes se encontram a Suíça, por todo o período, a Colômbia, entre 1958 e 1974, e Honduras, em 1971).

2. Obviamente a validade das nossas conclusões depende de quão razoável é este modelo, o qual, como todos os modelos, é passível de críticas (ver Laver e Schofield, 1990). Note-se, porém, que o que nos interessa é saber se as coalizões se formam, e não quais as coalizões que se formam. Um modo alternativo de se pensar as coalizões no parlamentarismo deve-se a Laver e Shepsle (1996).

3. Os independentes são considerados partidos compostos por um representante.

4. Mainwaring (1993) e Amorim Neto (2002) afirmam que, ao contrário do que ocorre no parlamentarismo, no presidencialismo a participação em um ministério não obriga os legisladores a apoiar o presidente. No parlamentarismo, os partidos podem usar o voto de desconfiança para disciplinar seus membros, o que não é possível no presidencialismo. No entanto, mesmo que a disciplina partidária seja menor no presidencialismo - algo sobre o qual somos agnósticos -, o efeito das coalizões presidencialistas é indeterminado: dependeria de quais partidos são menos disciplinados.

5. Provas baseadas nas eleições como ponto de retorno podem ser obtidas sob demanda.

6. Nesse tipo de literatura, um protocolo de barganha é a ordem em que os partidos tentam formar coalizões. O protocolo é fixo se for determinado por algum tipo de regra; é aleatório se essa regra só especificar as probabilidades dessa seqüência. Fixo ou aleatório, o protocolo faz diferença para os tipos de coalizão que se formam, mas não para o fato de serem ou não formadas.

7. O partido formateur de cada coalizão é sempre o primeiro da lista.

8. Exemplos disso são raros. Presidentes independentes governaram o Chile entre 1952 e 1957, Guatemala 1993-1995, Armênia 1991-1994, Quirguistão 1991-1999, Rússia 1991-1999 e Ucrânia 1991-1999.

9. Entre dezenove sistemas presidencialistas latino-americanos, o papel do Congresso na legislação orçamentária é restrito em todos, com exceção da Bolívia, Costa Rica, Guatemala, Honduras e Paraguai. Neles, o Congresso está limitado a propor emendas que não aumentem o déficit ou o gasto público, e em vários casos só pode fazê-lo com a aprovação prévia do presidente (ver Inter-American Development Bank, 1997:136).

10. Se o Congresso rejeita o orçamento, sanciona-se o orçamento do ano anterior na Argentina, Colômbia, Equador, El Salvador, Guatemala, Panamá, Paraguai, Uruguai e Venezuela. Se o Congresso não aprova o orçamento, a proposta do governo é sancionada na Bolívia, Colômbia, Costa Rica, Chile, Equador, Panamá, Paraguai e Peru. Dessa forma, uma verdadeira paralisia, na qual não existe nenhum orçamen- 
to, só é possível na Bolívia, Brasil e Honduras, onde o governo tem de encaminhar um novo orçamento e a Constituição não define nenhum status quo.

11. Excluímos os casos em que as coalizões são acordadas por um pacto pré-eleitoral dos partidos (a Suíça, em todo o período estudado, a Colômbia entre 1958 e 1974, e Honduras, por um ano).

12. Isto seria verdade se o tempo fosse medido em períodos muito curtos, enquanto neste trabalho medimos o tempo em anos. Para efeitos de comparação da freqüência de coalizões com a de eleições, consideramos que não havia governo nos anos em que ocorreram eleições antecipadas.

13. Os dados que informam esta análise se referem, às vezes, a cada ano de um governo, às vezes a uma coalizão específica, e, às vezes, ao mandato de um presidente ou a uma legislatura específica. Para criar observações anuais, atribuímos as informações para períodos mais longos a cada ano, tomando como referência a situação vigente em 31 de dezembro de cada ano.

14. Note-se, ademais, que esses dados estão sujeitos a um viés de seleção, o qual na verdade beneficia o nosso argumento sobre o presidencialismo. Visto que os governos parlamentaristas podem perder a confiança do Legislativo quando derrotados em matérias específicas, eles precisam ser mais cautelosos com relação aos projetos que submetem à apreciação. Os presidentes, por sua vez, podem ser mais impetuosos.

15. A hipótese de que $G$ é grande visa garantir que $g^{B}$ e $g^{P}$ sejam positivos.

16. Esta é a forma como Persson, Roland e Tabellini $(1997 ; 2000)$ modelam um sistema presidencialista genérico. Na verdade, as prerrogativas presidenciais de iniciativa legislativa variam entre os regimes presidenciais. Como, além disso, os autores acham que estão descrevendo "um sistema presidencial ao estilo dos Estados Unidos", e o sistema americano é único, porque nele o presidente não tem poderes formais de iniciativa legislativa, não é fácil entender o que eles têm em mente. Em vários sistemas presidencialistas, o Congresso só pode propor emendas que não aumentem o déficit ou os gastos do governo, mas em apenas cinco sistemas (Colômbia, Chile, Equador, Panamá e Uruguai) encontramos algo próximo à regra do "tudo-ou-nada", posto que emendas só podem ser consideradas se o governo estiver de acordo.

\section{REFERÊNCIAS BIBLIOGRÁFICAS}

ACKERMAN, Bruce. (2000), "The New Separation of Powers". Harvard Law Review, vol. $113, \mathrm{n}^{-} 3$, pp. 642-727.

AMORIM NETO, Octavio. (2002), “Presidential Cabinets, Electoral Cycles, and Coalition Discipline in Brazil", in S. Morgenstern e B. Nacif (eds.), Legislative Politics in Latin America. Cambridge, Cambridge University Press. 
AUSTEN-SMITH, David e BANKS, Jeffrey. (1988), “Elections, Coalitions, and Legislative Outcomes". American Political Science Review, vol. 82, no 2, pp. 405-422.

BEYME, Klaus von. (2000), Parliamentary Democracy: Democratization, Destabilization, Reconsolidation, 1789-1999. London, Macmillan.

CHEIBUB, José Antonio. (2002), “Minority Government, Deadlock Situations, and the Survival of Presidential Democracies". Comparative Political Studies, vol. 35, nํ 3, pp. 284-312.

DIERMEIER, Daniel e MERLO, Antonio. (2000), “Government Turnover in Parliamentary Democracies". Journal of Economic Theory, vol. 94, pp. 46-79.

GONZÁLEZ, Luis Eduardo e GILLESPIE, Charles Guy. (1994), “Presidentialism and Democratic Stability in Uruguay", in J. J. Linz e A. Valenzuela (eds.), The Failure of Presidential Democracy: The Case of Latin America (vol. 2). Baltimore, The Johns Hopkins University Press, pp.151-178.

HARTLYN, Jonnathan. (1994), "Presidentialism and Colombian Politics", in J. J. Linz e A. Valenzuela (eds.), The Failure of Presidential Democracy: The Case of Latin America (vol. 2). Baltimore, The Johns Hopkins University Press, pp. 220-253.

HUANG, The-fu. (1997), "Party Systems in Taiwan and South Korea", in L. Diamond et alii (eds.), Consolidating the Third Wave Democracies: Themes and Perspectives. Baltimore, The Johns Hopkins University Press, pp. 135-159.

INTER-AMERICAN DEVELOPMENT BANK. (1997), Report on Economic and Social Progress in Latin America. Washington, D.C., The Johns Hopkins University Press/IDB.

JONES, Mark P. (1995), Electoral Laws and the Survival of Presidential Democracies. Notre Dame, Notre Dame University Press.

KALANDRAKIS, Tasos. (2000), General Political Equilibrium in Parliamentary Democracies. Trabalho apresentado no Encontro Anual da American Political Science Association, Atlanta.

LAVER, Michael e SCHOFIELD, Norman. (1990), Multiparty Government: The Politics of Coalition in Europe. New York, Oxford University Press.

LAVER, Michael e SHEPSLE, Kenneth A. (1991), “Divided Government: America Is Not 'Exceptional'”. Governance, vol. 4, no 1, pp. 250-269.

. (1996), Making and Breaking Governments: Cabinets and Legislatures in Parliamentary Democracies. New York, Cambridge University Press.

LINZ, Juan J. (1978), The Breakdown of Democratic Regimes: Crisis, Breakdown, and Reequilibration. Baltimore, The Johns Hopkins University Press.

(1994), “Presidential or Parliamentary Democracy: Does it Make a Diference?", in J. J. Linz e A. Valenzuela (eds.), The Failure of Presidential Democracy: The Case of Latin America (vol. 2). Baltimore, The Johns Hopkins University Press.

— e STEPAN, Alfred. (1996), Problems of Democratic Transition and Consolidation: Southern Europe, South America, and Post-Communist Europe. Baltimore, The Johns Hopkins University Press. 
MAINWARING, Scott. (1990), "Presidentialism in Latin America”. Latin American Research Review, vol. 25, nº 1, pp. 157-179.

. (1993), "Presidentialism, Multipartism, and Democracy: The Difficult Combination". Comparative Political Studies, vol. 26, nำ2, pp. 198-228.

e SCULLY, Timothy R. (1995), "Introduction: Party Systems in Latin America”, in Building Democratic Institutions: Party Systems in Latin America. Stanford, Stanford University Press.

MAINWARING, Scott e SHUGART, Matthew S. (1997), "Conclusion: Presidentialism and the Party System", in Presidentialism and Democracy in Latin America. Cambridge, Cambridge University Press.

. (1998), “Juan Linz, Presidentialism, and Democracy: A Critical Appraisal”, in S. Mainwaring e A. Valenzuela (eds.), Politics, Society, and Democracy: Latin America. Boulder, Westview Press.

MAYHEW, David R. (1991), Divided We Govern: Party Control, Lawmaking, and Investigations 1946-1990. New Haven, Yale University Press.

NINO, Carlos Santiago. (1996), “Hyperpresidentialism and Constitutional Reforms in Argentina", in A. Lijphart e C. H. Waisman (eds.), Institutional Design in New Democracies: Eastern Europe and Latin America. Boulder, Westview Press.

PERSSON, Torsten, ROLAND, Gerard e TABELLINI, Guido. (1997), "Separation of Powers and Political Accountability". Quarterly Journal of Economics, vol. 112, pp. 1163-1202.

. (2000), "Comparative Politics and Public Finance". Journal of Political Economy, vol. 108, pp. 1121-1161.

PRZEWORSKI, Adam, ALVAREZ, Michael E., CHEIBUB, José Antonio e LIMONGI, Fernando. (2000), Democracy and Development: Political Institutions and Well-Being in the World, 1950-1990. New York, Cambridge University Press.

SAIEGH, Sebastian. (2001), Legislative Effectiveness of the Executive. Department of Politics/New York University. Manuscrito.

STEPAN, Alfred e SKACH, Cindy. (1993), “Constitutional Frameworks and Democratic Consolidation: Parliamentarism Versus Presidentialism". World Politics, vol. 46, no 1, pp. 1-22.

STROM, Kaare. (1990), Minority Governments and Majority Rule. Cambridge, Cambridge University Press.

SUNDQUIST, James L. (1989), "Needed: A Political Theory for the New Era of Coalition Government in the United States". Political Science Quarterly, vol. 103, pp. 613-635.

VALENZUELA, Arturo. (1998), "The Crisis of Presidentialism in Latin America", in S. Mainwaring e A. Valenzuela (eds.), Politics, Society, and Democracy: Latin America. Boulder, Westview Press. 


\section{ABSTRACT \\ Government Coalitions under Presidentialism and Parliamentarism}

Are government coalitions less frequent under presidentialism than under parliamentarism? The only difference between the two systems is that unscheduled elections are held under parliamentarism in those situations in which under presidentialism a majority legislative coalition opposes the executive. In both systems, portfolio coalitions are formed only when the formateur party and the one closest to it are relatively distant in policy terms. Otherwise, the formateur party governs alone, satisfied with the legislative outcomes. Hence, portfolio minority governments need not be less effective legislatively than coalition governments. Whatever is wrong with presidentialism, is not due to the difficulty of forming coalitions.

Key words: government coalitions; presidentialism; parliamentarism

\section{RÉSUMÉ \\ Coalitions de Gouvernement sous le Présidentialisme et sous le Parlementarisme}

Les coalitions au gouvernement seraient-elles moins fréquentes sous le régime présidentiel que sous le régime parlementaire? La seule différence entre ces deux systèmes réside dans le fait que, dans le parlementarisme, les élections non prévues s'effectuent dans les situations où, dans le présidentialisme, une coalition législative majoritaire s'oppose à l'exécutif. Dans les deux systèmes, les coalitions ministérielles ne se constituent que quand le parti formateur et celui qui en est le plus proche sont relativement distants en termes politiques. Sinon, le parti formateur gouverne seul, satisfait des résultats législatifs. C'est pourquoi il n'est pas nécessaire pour les gouvernements à minorité ministérielle d'être moins efficaces sur le plan législatif que les gouvernements de coalition. Tout ce qu'il y a de mauvais dans le présidentialisme n'est pas dû aux difficultés de former des coalitions.

Mots-clé: coalitions de gouvernement; présidentialisme; parlementarisme 